\title{
IGUALDAD Y JUSTICIA EN EL PENSAMIENTO DE HANS NEF
}

\section{Supuestos de la igualdad}

a) "Todo conocer principia con un distinguir. Incluso el conocimiento de que existe algo 'fuera de mí supone una distinción: el yo se coloca frente al no-yo y lo convierte en objeto distinto de él". ${ }^{1}$

El no-yo aparece ante el sujeto como una abigarrada multiformidad. El cognoscente es capaz de conocerla y afirmarla si distingue y ordena sus elementos. Y las relaciones entre éstos pueden ser establecidas en cuanto sus términos han sido separados entre sí.

Pero si tanto las propiedades como las relaciones entre los elementos sólo son accesibles a la conciencia cuando los hemos diferenciado, resulta que el aserto de que dos objetos son iguales necesariamente supone su previa distinción. Expresado en otro giro: como los juicios sobre realidades implican siempre un distinguir, los que afirman la igualdad de dos o más cosas no pueden escapar a la regla.

Este principio - afirma Nef_- es formulable aun antes de definir el concepto de igualdad, ya que constituye un "caso de aplicación" del axioma de que "todo conocimiento y todo juicio suponen un distinguir o diferenciar"."

Windelband formula la misma idea con estas palabras: "Las categorías de la reflexión principian con la actividad diferenciadora como primera y básica función judicativa; pues para relacionar en alguna forma los contenidos de las representaciones ante todo hay que diferenciarlos y mantener su diferencia". ${ }^{3}$

Si el juicio de que dos objetos son iguales presupone su diferenciabilidad, de aquí resulta que sólo puede ser igual lo diferente.

Este 'paradójico aserto' es, a los ojos de Nef, un analogon del que dice que "únicamente puede transformarse lo que permanece". Ninguno de los dos encierra, sin embargo, un contenido paradójico; más bien se trata de "agudas intelecciones", a las que se llega por un camino "estrictamente lógico". ${ }^{4}$

Al sostener que sólo puede ser igual lo que difiere, con ello queda dicho

1 Hans Nef, Gleichheit und Gerechtigkeit, Polygraphischer Verlag AG., Zürich, 1941, pág. 3.

2 Nef, opus cit., pág. 4 .

3 Windelband, Die Prinzipien der Logik, pág. 29, 'citado por Nef en Gleichheit und Gerechtigkeit, pág. 4.

4 Nef, opus cit., pág. 4 . 
que la igualdad o la diferencia siempre se dan entre dos cosas cuando menos. En cuanto uno de los objetos comparados no es el otro, declaramos que son dos y no uno, y establecemos su dualidad por. las diferencias que los separan. La diferencia es, por ende, el primer supuesto de la igualdad. Asi lo indica el principio de que sólo lo diverso puede ser igual. O, para decirlo con Linke: "igual es lo diverso, en cuanto algo le es común".5

b) Los juicios sobre la igualdad o la diferencia tienen un segundo supuesto: que los objetos a que aluden sean comparables entre sí. Podría objetarse, advierte Nef, que a primera vista todas las cosas parecen susceptibles de parangón, en cuyo caso aquel atributo les correspondería siempre, en vez de ser nota especial de algunas. "De hecho pueden ser comparados el sol y una mesa, un león y un reloj; y el resultado de compararlos se expresará diciendo que esos objetos son completamente dispares. Pero nunca diremos que son iguales o desiguales entre sí; más bien aparecen como no susceptibles de comparación." " Precisamente cuando lo comparado aparece como "no comparable", resulta patente que cabe hablar de comparabilidad en un sentido más riguroso o estricto. La circuristancia de que ciertas realidades toleren que se las juzgue desde el punto de vista de la igualdad o la desigualdad, y otras no lo toleren, revela que al supuesto de la diferenciabilidad, primeramente examinado, hay que añadir otro, el de que las cosas sean comparables en la acepción estricta o rigurosa del término. Diferencia y comparabilidad son, pues, condición necesaria de los juicios que afirman que dos o más objetos son iguales.

¿Cuándo puede hablarse de comparabilidad, en el segundo sentido?... Tal atributo conviene a dos o más cosas, responde Nef, cuando tienen algo en común. "Intencional y provisoriamente decimos 'algo', pues en este orden de consideraciones hay que proceder con cautela. Cualquicra otra cxpresión en que pudiera pensarse sería probablemente equivoca. Puede quizás sentirse la tentación de afirmar que para que haya comparabilidad es necesario que una cualidad o propiedad sean comunes. Pero esto tendría que precisarse aclarando que no se alude realmente a cierta propiedad sino, más bien, en cierto modo, a la posibilidad de tenerla. Así, por ejemplo: para la comparabilidad no se exige, verbigracia, que dos cosas exhiban ambas la cualidad de la rojez, sino solamente que sean de color." 7

A fin de precisar el sentido de su doctrina sobre los supuestos de la igualdad y la diferencia, Nef ofrece el siguiente ejemplo: si estamos en presencia de dos bolas y comprobamos que tienen coloración, podremos compararlas desde este punto de vista. Supóngase que ambas son rojas. Diremos entonces

5 Grundfragèn der Wahrnehmingslehre, pág. 302, nota 1, citado por Nef en la pág. 6 de Gleichheit und Gerechtigkeit.

6 Nef, opius cit., pág. 7 .

7 Nef, opus cit., pág. 7 . 
que son iguales en ese respecto. Pero si una es roja y la otra azul, habrá que decir que son desiguales, en el mismo respecto.

Que las dos estén coloreadas es lo que determina su comparabilidad. En otras palabras: para afirmar (o negar) que sean iguales —en tal respecto- es indispensable que tengan aquel atributo. A través del ejemplo se percibe la diferencia entre las nociones de comparabilidad e igualdad: la coloración de las bolas permite comparärlas en el respecto indicado; la circunstancia de que sean rojas condiciona su igualdad. Que el otro supuesto de la igualdad se da en el caso es evidente, ya que se trata de dos bolas, y no de una.

La base común de comparabilidad es llamada por los lógicos tertium comparationis, y debe permanecer idéntica en el comparar. Por ello William Stern asevera que la igualdad es una relación trimembre, puesto que requiere, "además de las dos cosas comparadas, $a$ y $b$, una tercera $c$ (tertium comparationis)".

"Sólo en cuanto una y la misma cosa se convierte en punto común de referencia de otras dos, hay igualdad entre éstas; la identidad de $c$ consigo misma es un supuesto de la relación de igualdad entre $a$ y $b . " 8$

Nef piensa que la identidad del tertium comparationis, más que de la igualdad, es presupuesto de la comparabilidad. El tertium comparationis, en el ejemplo anterior (coloración de las bolas), ès la base que permite compararlas. La condición de la igualdad, en el propio caso, es otro elemento común, conexo con el primero: la rojez, propiedad de los objetos en el respecto del color. Tenemos, pues, que vérnoslas con dos elementos comunes: la cualidad de lo coloreado (supuesto de la comparabilidad) y la propiedad común de la rojez (condicionante de lā igualdad).

Todo comparar es un diferenciar, pero un diferenciar que pretende esclarecer "en qué respecto los objetos parangonados son iguales, y en qué otro son desiguales".9 Tal esclarecimiento sólo puede lograrse cuando las diferencias no son simplemente puestas en conexión, sino relacionadas desde cierto punto de vista. Las cosas han de ser comparables en alguin respecto $\ddot{0}$, de lo contrario, el .paralelo es imposible. ¿Por qué - pregunta Nef- no se nos ocurre comparar la electricidad con un triángulo, un triángulo con un clefante o el tamaño de un objeto con el color o la durezá de otro? Al punto advertimos que semejantes cotejos son imposibles: carecemos de base para comparar las cosas que resultan dispares en todos los respectos. Reflexionando sobre esos ejemplos se advierte cómo los tertia comparationis son; ante todo, supuesto de la comparabilidad y, sólo en forma indirecta, de la igualdad. libro.

8 W. Stern, Person und Sache, Vol. I; p. 349, f., citado por Nef en la pág. 8 de su

9 Ulrici, Compendium dér Logik, 93, ff. citado por Nef en Gleichheit und Gerechtigkeit, pág. 9 . 


\section{Igualdad absoluta e igualdad relativa *}

Los anteriores análisis nos han conducido a la conclusión de que sólo podemos declarar igual o desigual to que es diferente $\mathrm{y}$, a la vez, comparable. Comprobamos la igualdad - lo mismo que la diferencia- en el acto de comparar.

Tal acto consiste en considerar alternativamente cosas diferentes y parangonables desde el punto de vista de un elemento que les es común, el llamado tertium comparationis. Como la igualdad presupone ese tercer término, y el parangón sólo es posible en relación con él, el resultado del cotejo sólo puede ser la comprobación de una igualdad o desigualdad de los objetos, en ese respecto común. Entre las cosas no hay igualdad total o absoluta; sino sólo relativa, esto es, desde el punto de vista común del tertium comparation is. Pero cuando dos de ellas aparecen como iguales en todos los respectos, cuando, verbigracia, dos bolas rojas son del mismo tamaño: ¿cabe hablar de igualdad absoluta? De hecho - escribe Nef - parece justificado prescindir, en tal coyuntura, de cualquier limitación o reserva, y sostener, sin más, que "son iguales". Sin embargo, una consideración más atenta revelaría que, incluso en la hipótesis examinada, hay un respecto en que aquellos objetos no sólo no son iguales, sino que tienen que ser, a fortiori, diferentes. Ese respecto es el del lugar que ocupan. En otros respectos podrán ser iguales, pero nunca en lo que concierne al espacio en que se hallan. Si ocupasen el mismo - arguye Nef- no se daría el supuesto de la diferencia que, según sabemos, es condición necesaria de toda igualdad. La posibilidad de distinguir los objetos del orden sensible, deriva, precisamente, de que se encuentran en lugares distintos. De lo contrario, sería imposible diferenciarlos. Lo que de modo concomitante ocupa el mismo espacio es lo mismo, es idéntico, es uno. Igual sólo puede ser lo diferente, y la relación de igualdad exige, al menos, dos términos. Luego si dos bolas son iguales en otros respectos, en el del lugar que ocupan no podrán serlo. Su igualdad en tal respecto es impensable, porque, si ocupasen el mismo espacio, no habría dos bolas, sino una, idéntica a si misma, lo que suprimiría el primer supuesto de la igualdad, el de la diferencia o discernibilidad de los objetos. ${ }^{10}$

10 La tesis de que las cosas "iguales" tienen al menos que diferir en cuanto al espacio que ocupan, es, a mi juicio, una simplificación de lo que en realidad ocurre. ¿Será verdad, para volver al ejemplo, que las bolas que declaramos 'iguales' difieran sólo en cuanto al lugar en que se encuentràn?... Si las dos son de marfil: ¿diremos que su materia es igual?... Aun cuando pueda afirmarse que es la misma, esto no significa que sea imposible diferenciar el marfil con que está hecha la bola de la izquierda del que sirvió para hacer la de la derecha. En el respecto que examinamos hay, pues, igualdad especifica (y, por ende, no individual) entre los objetos comparados. De lo contrario, tendria que hablarse de identidad, no de igualdad de las bolas. Cosa análoga debe decirse del color, la forma, el peso, etc. El color, la forma y el peso de las bolas iguales en tales respectos pueden individualizarse - $\mathrm{y}$, consecuentemente - distinguirse, en función del espacio en que 


\section{Definición de la igualdad}

La igualdad absoluta - al menos en el orden real_ es imposible. Sólo podemos hablar de 'igualdad respecto a' o 'relativamente a'. Lo dicho tiene, según Nef, consecuencias importantes para la definición de la igualdad. Sería un contrasentido querer definirla como igualdad a secas, y decir: "Igualdad es..." Tal igualdad ni existe ni es definible y, por tanto, no puede aparecer como definiendum: Lógicamente sólo cabe definir la igualdad relativa, o igualdad 'en tal o cual respecto'.

Hablar de lo igual es hacer un enunciado que se refiere a dos cosas cuando menos, considerándolas en forma simultánea. No se alude a una y luego a la otra, sino que concomitantemente se dice algo de entrambas. No puede, pues, tratarse de una propiedad, porque las propiedades pertenecen a las cosas como objetos singulares o aislados. Éstas sólo en su singularidad pueden tener propiedades, ser, por ejemplo, rojas o esféricas. 'Igualdad' no es, por consiguiente, una propiedad de aquéllas. No es que una sea 'igual' y la otra 'igual', en el sentido en que decimos, verbigracia, que una es un cubo y otra un cilindro. Lo 'igual' no está en cada una de las comparadas; más bien 'remite' de una a la otra. No se trata, pues, de una propiedad, sino de una relación entre dos términos. Los objetos 'iguales' son referidos uno al otro en una "visión conjunta", y el resultado de compararlos es la comprobación de un nexo entre ambos.

El genus proximum de la definición queda así establecido: 'igualdad es una relación'. ¿Cuál es la diferencia específica?...

Lo que caracteriza al nexo entre cosas iguales es que tienen algo en comun. Si son iguales respecto al color, ello se debe, por ejemplo, a que ambas son rojas. Y si coinciden en cuanto a su forma es porque, también en tal respecto, comparten otra propiedad, la de ser, verbigracia, cuerpos esféricos. La igualdad relativa puede, pues, definirse así: Igualdad 'respecto $a^{\prime}$ es la relación entre dos cosas que tienen, en tal respecto, una propiedad comun.11

\section{Igualdad e identidad}

Aun cuando verbalmente afines, estos conceptos deben ser cuidadosamente distinguidos. El lenguaje cotidiano revela que se trata de nociones distintas, e indica en qué consiste la diferencia. Suele decirse que la segunda no indica 'igualdad' de entidades diferentes, sino de una cosa consigo misma.

se dan. Por ejemplo: el color rojo de la bola de la izquierda aparece en la superficie -y el lugar - de dicha bola, no en la superficie $\rightarrow$ y el lugar — de la otra. Lo mismo es aplicable a la forma, el peso, etcétera.

11 Nef, opus cit., pág. 15 . 
Pero este giro es una contradictio in adjecto, ya que no alude a dos o más cosas. Cuando sólo viene en cuestión una, la igualdad, tomada en forma estricta, no puede darse. Es entonces cuando hablamos de 'identidad'. En cuanto este último término sólo se refiere a un objeto, la identidad resulta esencialmente diversa de la igualdad, que siempre se da entre varios.

Husserl menciona algunos casos en que indebidamente se habla de identidad, cuando debiera hablarse de igualdad. "Tratándose de cosas iguales hablamos a menudo de la misma. Decimos: el mismo armario, la misma falda, el mismo sombrero, por hallarnos ante productos que, elaborados según el mismo patrón, son completamente iguales entre sí, mejor dicho, iguales en aquello que para nosotros tiene interés." Éstos son ejemplos de 'giros impropios' sobre 'identidad'. "Nos pareceria unà inversión de lo que en realidad ocurre que se pretendiese, aunque no fuera sino en el orden sensible, definir la identidad como caso limite de la igualdad. La identidad es absolutamente indefinible; no así la igualdád." 12 Hablar de "igualdad de una cosa consigo misma' es sólo un artificio; se echa mano de él precisamente por la imposibilidad de definir aquel concepto.

Nef recuerda la opinión de Koppelmann, para quien sí puede existir una 'igualdad total'. Es la igualdad 'en todos los respectos'. De cualquier modo, añade el mismo autor, es difícil establecerla, pues nunca estaremos seguros de haber agotado todos esos respéctos. Pero aquí "no sólo hay imposibilidad de comprobación, sino imposibilidad lógica; . la igualdad total no puede ser pensada, porque se confundiría con la identidad, y ésta no es ya igualdad". ${ }^{13}$

\section{Relatividad de la igualdad}

La igualdad, en el orden sensible, es necesariamente relativa, puesto que las cosas sólo en cierta relación pueden ser iguales, y en otra tienen que ser, al propio tiempo, diferentes. Tan pronto como en un respecto no coinciden, en ese mismo respecto resultan, a fortiori, distintas. El 'mínimum' de desigualdad es, para Nef, la diferencia en cuanto al lugar, la posición en el espacio. Pero esa desigualdad constituye únicamente un 'mínimum'; sólo en casos extremos, objetos que desde otros puntos de vista son iguales, exhiben tal desigualdad de modo exclusivo. Se trata del caso limite de la igualdad, no de la identidad. En contraste con lo que ocurre cuando estamos ante lo idéntico, el supuesto de la diferenciabilidad subsiste aquí; hablamos de caso limite porque en él se da la mínima diferencia indispensable.

'Podemos, pues, decir: los objetos que en uno o varios respectos son igua-

12 E. Husserl, Logische Untersuchungen, Vol. II, Parte I, pág. 112, citado por Nef en la pág. 20 de su ensayo.

13 Nef, opus cit., pág. 29. 
les, necesaria y simultáneamente son, en otro $u$ otros, diferentes. Este principio tiene consecuencias importantísimas pará la doctrina de la justicia.

Quien habla de lo 'igual' y lo 'desigual' atiende, de modo exclusivo, a un aspecto de las cosas, y descuida los demás.

¿Por qué se produce tal descuido?...

Obviámente, porque el sujeto sólo toma en cuenta los aspectos que le interesan o tienen importancia para el logro de sus fines.

Llegamos así a un punto fundamental. Pues si los juicios sobre la igualdad o la diferencia dependen del interés de la persona, de sus necesidades o propósitos, en esos juicios está implicado un momento subjetivo. "Cuando elijo el punto de vista desde el cual quiero contemplar las cosas, ciñéndome a criterios que no están en conexión con ellas, sino con mi situación personal, el hecho de que las llame iguales o desiguales resulta indirectamente condicionado por ese elemento subjetivo." 14

Todos los objetos del mundo real son, a un tiempo, iguales y desiguales. Que aparezcan ante el sujeto en una $\mathbf{u}$ otra de las dos formas es algo que no está en ellos; depende del ángulo visual en que se coloca quien los compara. El punto de vista es elegido por la persona de acuerdo con su arbitrio; pero este último término debe entenderse bien. Para el sujeto, la elección está condicionada por momentos objetivos $\mathrm{y}$, en tal sentido, no es arbitraria. Pero, desde el punto de vista de las cosas, obedece a factores ajenos a ellas y tiene, por ende, carácter subjetivo.

Piénsese, dice Nef, en la debatida cuestión de la igualdad del sufragio. El problema consiste en saber si todos los hombres son esencialmente iguales $y$, por consiguiente, a todos debe atribuirse el mismo derecho de voto, o lo esencial está en sus diferencias y, por ende, no es correcto otorgarles derechos iguales. Al abordar el tema, unos llaman sencillamente a los hombres 'iguales'; otros los llaman sencillamente 'desiguales'; pero los seres humanos somos ambas cosas a la vez. Que los primeros atiendan exclusivamente a unos aspectos y los segundos a otros, obedece a la postura que cada uno subjetivamente adopta. El aserto de que en la cuestión del sufragio hay que atender a ciertos rasgos de la realidad humana y descuidar otros a los que se niega importancia, a fin de cuentas depende de concepciones últimas sobre la vida y los valores. $Y$, relativamente al objeto que se juzga, tales concepciones aparecen como puramente subjetivas.

Nef opina que el principio 'toda igualdad es relativa', no tiene validez en el campo de la matemática. Cuando el matemático habla de igualdad no piensa en igualdad 'en-tal o cual respecto', sino en una igualdad absoluta. La explicación reside en que la igualdad matemática es 'cuantitativa'. La cantidad es abstraída de los objetos y considerada aisladamente. Y no procede preguntar en qué respecto o relación existe, porque ella misma es ya

14 Nef, opus cit., pág. 26. 
una relaciỏn. Si dos cosas son cuantitativamente iguales, habrá que sostener que son iguales sin más, o en absoluto, pues ya no existe otro respecto en que pudieran, al propio tiempo, diferir.

El principio de la relatividad de la igualdad vale, pues, en el orden de las cosas reales, pero no para el dẹl ser ideal, en que los objetos matemáticos se hallan insertos.

\section{Igualdad y desigualdad humanas}

"El derecho -escribe Nef- es creado por los hombres y para los hombres. Es una ordenación para la vida humana en común, que impone deberes a cada individuo y le confiere facultades. Toda norma objetiva guarda en última instancia alguna relación con el hombre, y éste es en algún sentido regido por ella. La creación de preceptos jurídicos se vincula necesariamente a las personas y a su peculiar naturaleza. Esto puede no aparecer siempre de modo claro, pero en último análisis tiene que manifestarse en cada caso, y no puede ocurrir de otra suerte, pues lo que a fin de cuentas hace indispensable determinada regulación es la naturaleza peculiar del hombre (o de ciertos hombres). Si los hombres, o ciertos hombres, fuesen distintos, esa regulación no sería necesaria o correcta o, en otras palabras, el orden jurídico sería diferente." 15

Si concebimos a los seres humanos desde el punto de vista de la doctrina de la igualdad, para aplicarles los resultados obtenidos, habrá que reconocer que son iguales y desiguales a la vez, vale decir, iguales en ciertos respectos y desiguales en otros. ${ }^{16}$

El caso límite del minimum de desigualdad, antes mencionado, no se da entre los humanos. Por experiencia sabemos que los respectos en que difieren son muchos y siempre superan a aquellos en que resultan iguales.

Preguntémonos, primeramente, en qué sentido cabe afirmar la igualdad de todos. Lo que los iguala es su humanidad, esto es, el hecho de ser hombres. "Tal cuestión se confunde con la de la definición del individuo humano, pues en la fórmula definitoria tiene que manifestarse lo específico, que separa al correspondiente concepto de otras nociones. Encontrar el genus proximum no resulta difícil: el hombre es un viviente, pertenece al sistema de todo lo que vive. Pero no es fácil indicar la differentia specifica, decir qué distingue a los hombres de los demás vivientes. De una cosa debemos tener conciencia: se trata del problema básico de la antropología. Desenvolver tal cuestión es plantear el problema antropológico fundamental." 17 
Si los hombres coinciden siempre en su humanidad, múltiples diferencias los separan: sexo, edad, aptitudes intelectuales, etcétera. Pero no todos los humanos son, en tales respectos, desiguales. Unos resultan, en determinadas características, diferentes de los demás, y otros, en los mismos aspectos, iguales entre sí. Atendiendo, ya a las notas comunes, ya a las distintivas, podemos formar numerosos grupos. De esta especie son los que integran los varones, las mujeres, los menores de edad, los divorciados, los imbéciles, etc. Un mismo hombre puede, naturalmente, pertenecer a más de una de tales clases. "En un respecto es igual a unos; en otro, a otros. Nuevamente se trata de la relación en que los seres humanos son considerados. Si se les llama iguales en una relación diferente del simple ser hombres y, por ende, se les incluye en un grupo, ello generalmente ocurre de acuerdo con cierto punto de vista. Cuando se habla de igualdad o de desigualdad siempre hay que preguntar por ese respecto o punto de vista. Como los agrupamientos se entrecortan o superponen en variadas formas y, por tanto, lo propio acontece con las igualdades y las diferencias, en cada caso en que los hombres sean llamados iguales o desiguales habrá que indicar la relación en que así se les considera." 18

Mientras que en su humanidad todos coinciden, en su individualidad difieren todos. La individualidad distingue a cada uno de los demás; tal nota constituye, pues, el 'contrapolo' de la otra. Pero si prescindimos de estos extremos, habrá que reconocer que en otros respectos los hombres pueden ser, ya iguales, ya desiguales entre sí. Esto permite incluirlos en grupos de diferente extensión, que se entrecruzan en múltiples formas.

Nef opina que ni la Antigüedad ni la época moderna formularon estos principios con el rigor de los pensadores medievales.

"Cuando una cosa es tan ampliamente concebida por nosotros que podemos reconocerla en su determinación espacial y numérica -escribe Adelard von Bath en su obra De eodem et diverso- le damos el nombre de 'individuo', como al referirnos a Sócrates o a Platón. Pero cuando sólo tomamos en cuenta las peculiaridades expresadas por la palabra 'hombre', lo que obtenemos es el concepto especifico. Si se examinan, por último, las determinaciones que abarca el vocablo 'viviente', entonces se llega al concepto genérico. Pero ni en la concepción especifica son suprimidas las formas o peculiaridades individuales, ni en la genérica las determinaciones características de la especie, sino sólo hechas a un lado, desatendidas, intencionalmente olvidadas (obliviscuntur)". ${ }^{19} \mathrm{El}$ concepto especifico 'hombre' - comenta Nef_- es obtenido, y lo común a los hombres descubierto, cuando prescindimos o 'nos olvidamos' de los aspectos constitutivos de la individua-

18 Nef, opus cit., pág. 43 .

19 Hans Willner, Des Adelard von Bath Traktat de eodem et diverso, p. 54 f.f., citado por Nef en Gleichheit und Gerechtigkeit, pág. 4.5 . 
lidad de cada ser. Los mismos pensamientos son expuestos, si bien con mayor precisión, en los siguientes pasajes de un tratado anónimo sobre los géneros y las especies: "Sócrates, como el individuo que es, considerado con todas sus peculiaridades individuales, difiere de los demás hombres por su socratidad, por la idea de Sócrates de que es el único portador sustancial". "Pero si se le considera como hombre, en lo que atañe a tal status resulta, a la vez, diferenciable e indiferenciable. Es diferenciable de toda cosa existente en la medida en que, como tal Sócrates, no es ninguna otra cosa, ni respecto del status. hombre ni de ningún otro status. Al propio tiempo, es indiferenciable, es decir, semejante a Platón y a otros individuos, en cuanto es, como los demás, un hombre." 20 .

\section{Definición de la justicia}

Al abordar el tema de la definición de la justicia, Nef empieza por distinguir las acepciones formal y material del vocablo. Justicia, en el primer sentido, es conformidad de un acto, una institución o una norma a las prescripciones del derécho positivo. 'La sentencia 'justa', la resolución administrativa 'justa', el juez 'justo', todo esto es llamado así "en el sentido de apegado a la ley, de fiel a ella". En tales casos, el criterio para juzgar de la justicia de un comportamiento, un fallo judicial o una persona, lo ofrecen las prescripciones en vigor. Pero, en un segundo sentido, se habla de la justicia o injusticia de los preceptos legales, o de la justicia o injusticia de quien los formula.

AI jurista teórico suele bastarle la indicada dicotomía; pero existen otras manifestaciones que no guardan conexión con el derecho positivo. Así como hablamos del juez o del legislador 'justo', podemos aludir a la 'justicia' de un maestro o de un crítico, referirnos a la de Dios e incluso a la del destino. El problema es descubrir una definición aplicable a todos estos usos.

Encontrar el género próximo, dice Nef, suele ser menos difícil que dar con la differentia specifica. Pero en el caso no ocurre lo propio, porque los conceptos superiores que las definiciones señalan son distintos siempre. -A unos les parece que la justicia es una virtud; otros la conciben como acto; otros, como intención. No pocos ven en ella una idea o un ideal, y muchos Ia caracterizan como norma o exigencia. Por último, hay quien la define como valor.

Para Sócrates es la virtud de obediencia a la ley; para Platón, ya el acuerdo entre las partes del alma, ya la armonía de las clases dentro del Estado. Aristóteles - que primeramente recoge la noción platónica de la jus-

20 Willner, Des Adelard von Bath Traktat de eodem et diverso, p. 64 f.f., citado por Nef en la pág. $4^{6}$ de Gleichheit und Gerechtigkeit. 
ticia como suma o síntesis de las demás virtudes- la estudia después como virtud especifica, y le dedica las consideraciones que tan honda influencia han ejercido en los filósofos posteriores.

Al enorme influjo del Estagirita - dice Nef- hay que atribuir el hecho de que "también en la Edad Media y en la época moderna sea la justicia considerada por muchos como una virtud, y que en numerosos pasajes aparezca la distinción entre lo justo como virtud universal y virtud particular". ${ }^{21}$

Otros autores buscan el genus proximum en el concepto de acto. Que lo hagan así resulta explicable cuando se reflexiona en que el hombre que posee la virtud de la justicia y es, en general, Ilamado 'justo', puede alguna vez proceder injustamente. Y a la inversa: un solo acto de justicia no basta para convertir a nadie en 'varón justo'.

Nef refiérese seguidamente a la célebre fórmula de Ulpiano. Cuando el famoso jurisconsulto define la justicia como constans et perpetua voluntas, ius suum cuique tribuendi no piensa, según nuestro autor, en el sentido psicológico o filosófico del término 'voluntas'. Spinoza, que se apoya en la definición romana, ha traducido 'voluntas' por 'intención', "lo que no aclara esencialmente el asunto". 22

"En la época moderna dominan otros conceptos. Se ve principalmente en la justicia una exigencia dirigida a la conducta y, sobre todo, al derecho. Se habla, por tanto, de su idea, y por tal se entiende una pauta o directriz. Acentúase el aspecto normativo y entonces se la designa como ley, como norma, como principio rector..." "La moderna 'ética material', la subsume, por su parte, bajo un concepto distinto. Para esa doctrina es la justicia un valor. Le corresponden los atributos propios de lo valioso, y se llega más cerca de su esencia cuando se la compara y relaciona con otros valores. Así la conciben, por ejemplo, Nicolai Hartmann y Eduardo Spranger. Entre los juristas, Julius Binder, por ejemplo, ha hecho referencia a su carácter axiológico." 23

¿Quién tiene razón? - se pregunta Nef. Y responde: la tienen todos, sea que entiendan la justicia como virtud, conducta, intención, 'idea, norma, principio, ley o valor. Lo justo puede ser subsumido bajo todos estos términos, sin resultar por ello equívoco. $Y$ es que en realidad no se trata de conceptos diversos sino, más bien, de distintas formas de manifestación de un solo objeto. Lo que salva la unidad conceptual es lo especifico de lá justicia, que se mantiene invariable siempre. Habrá unidad de concepto si podemos demostrar que la diferencia específica es la misma en todo caso, sea cual fuere el género próximo. "Entonces podrá hablarse de un concepto unitario, pese a la posibilidad de que se admitan diferentes nociones supe-

21 Nef, opus cit., pág. 59 .

22 Nef, opus cit, pág. 61.

23 Nef, opus cit., pág. 61 . 
riores." Además, los conceptos que suelen ser empleados como género próxi mo, si bien verbalmente son distintos y despiertan diferentes representaciones, "en el fondo coinciden todos" $y$, en rigor, son "facetas diversas del mismo fenómeno". Para percatarse de ello basta con examinar detenidamente algunos de los ejemplos citados. En el caso del legislador que expide leyes justas, verbigracia, perfectamente podemos decir que posee la virtud de la justicia. Pero ésta se manifiesta en la expedición de dichas leyes y, por tanto, tradúcese en actos, en formas de conducta. Además, su comportamiento es calificado de 'justo' en la medida en que se ciñe a una norma o criterio de justicia. Al mismo tiempo, a través de su tarea específica, el órgano legislativo realiza el valor del mismo nombre.

La noción que completa las diversas definiciones está en el concepto de igualdad o, para expresarlo con mayor rigor, en el de igualdad de tratamiento (en alemán: Gleichbehandlung). A fin de explicar el sentido de estos términos Nef se vale de una serie de ejemplos. "Nuestro escenario - _escribe al poner el primero_ será el guardarropa de una sala de conciertos o de un teatro. Al terminar la representación el público se precipita hacia el mostrador del guardarropa, para recibir sus prendas de la encargada. A todo lo largo del mostrador se colocan, una al lado de la otra, to personas, y detrás de ellas se forman 5 hileras más de 10 personas cada una. La empleada trae las prendas de la persona que está en el extremo ( $\left.\mathrm{N}^{\circ}{ }_{1}\right)$ y después las de la persona que se halla a su lado (No 2). Mientras sirve a ésta, la persona que se hallaba detrás de la $\mathrm{N}^{0}$ I ocupa el lugar que la misma tenía. Después de atender a la persona No 2 , la encargada del guardarropa no se dirige a la persona $\mathrm{N}^{\circ}$ 3, sino a la que ocupó el lugar de la No 1 . Entretanto; el lugar de la persona $\mathrm{N}_{2}{ }_{2}$ es ocupado por la $\mathrm{N}_{2}{ }_{2}$ de la hilera posterior, que es atendida inmediatamente después. $\mathrm{Y}$ asi sucesivamente. Las colocadas detrás de las personas 1 y 2, y las que sucesivamente van ocupando esos puestos, son despachadas, en tanto que las que ocupan los puestos 3 a 10 de la primera hilera tienen que esperar. Represéntese el lector cómo reaccionarían los perjudicados. ¿Qué opinarían de la actitud de la empleada? Dirían, sin dudá, que es injusta. ¿Injusta por qué? Sencillamente porque los que han llegado más tarde no deben ser atendidos antes que los que llegaron primero. Y si se preguntara cómo se debe proceder para hacerlo en forma justa, habría que contestar que lo correcto es atender ante todo a la primera hilera (personas 1 a 10 ), para proseguir con la número 1 de la segunda, a fin de que todos tengan que esperar más o menos lo mismo. El tratamiento justo consiste, pues, en un tratamiento igual." 24

Otro ejemplo de justicia 'extrajurídica' es el del maestro que no otorga la misma nota a todos los alumnos, sino que atiende, al calificar sus trabajos, al mérito de cada uno. En cambio, del que da a un discípulo consentido

24 Nef, opus cit., pág. 69. 
una calificación que no merece, o exige a los de la clase inferior un esfuerzo igual al exigido a los de la superior, decimos que es 'injusto'. Podrá o no ser un buen maestro, pero su justicia depende de que juzgue en forma igual los rendimientos iguales, y desigualmente, pero en proporción a su desigualdad, los desiguales.

Tercer ejemplo: "cuando el señor crítico musical redacta su primera crónica y, con sorpresa de todos, contrariando la satisfacción general, es excesivamente duro con el ejecutante, no por ello se le llama injusto. Pero si en una segunda ocasión, a propósito de una ejecución igual o incluso peor, publica una crónica desproporcionadamente favorable, no podrá evitar que se le haga el reproche de que ha procedido injustamente. Sería justo, en cambio, si cada vez 'midiese con la misma vara'; sea o no un crítico estricto, la justicia exige que juzgue en forma igual lo que es igual".25

Un ejemplo interesante de justicia 'jurídica' es el planteado por el artículo 274 del Código Civil suizo. De acuerdo con tal precepto, los padres ejercitan conjuntamente, durante el matrimonio, la patria potestad sobre los hijos, pero, cuando hay discrepancia de opiniones, la decisión corresponde al padre. Se ha dicho que lo justo sería que los dos ascendientes tuvieran iguales derechos. Sólo que, en el caso, la igualdad resulta imposible, puesto que uno de los cónyuges ha de poder pronunciar la palabra decisiva.

Cosa análoga ocurre en caso de empate de una votación. "El voto de calidad -escribe Nef_- da origen a una desigualdad del mismo jaez, en cuanto el presidente, cuyo voto no debiera valer más que el de los otros, dë hecho tiene dos. Pero esta desigualdad es inevitable, puesto que hay que resolver de alguna manera, y ello no es posible si sólo se atiende a la igualdad." 26

En el campo del derecho procesal -para citar otro de los ejemplos del jurista suizo- el postulado audiatur et altera pars vale también como regla de justicia. Sería injusto que dentro de un procedimiento en que intervienen dos partes, sólo se oyese a una de ellas.

Después de poner otros ejemplos, Nef concluye que en todos los examinados hay siempre una referencia a la igualdad. "Lo' justo se hace regular. mente consistir en cierta igualdad de tratamiento. Por cllo se habla de trato proporcional, de igual medida, de iguales derechos o deberes o de cierta compensación. Siempre se juzga que alguien procedió contrariamente a la igualdad, en vez de atenerse a ésta. En otras palabras: lo exigido, en cada caso, era un trato igual. Estos son los dos momentos, el de igualdad y el de tratamiento, que queremos considerar característicos, uniéndolos en la expresión igualdad de tratamiento. La encargada del guardarropa debía haber tratado a todos en forma igual, para ser justa; lo mismo el maestro a sus

25 Nef, op̣us cit., pág. 70.

26 Nef, opus cit., pág. 73. 
alumnos. El crítico debía haber medido con la misma vara y, en este sentido, tratado en forma igual a los juzgados por él. El legislador, por su parte, debe repartir equitativamente derechos y deberes, para hacer leyes justas. $\mathbf{Y}$ el destino es motejado de "injusto" porque no concede lo mismo a todos los hombres; pero a Dios lo llamamos 'justo' porque reparará esa injusticia $y$, por ende, volverá a tratar igualmente a todos." 27

\section{La noción de tratamiento}

'Tratamiento' quiere decir tanto como conducta de un sujeto dirigida a otro $u$ otros. Ya Aristóteles, al referirse a la justicia como virtud universal -recuerda Brunner - la distingue de las demás por esta referencia a terceros. "Tal justicia - escribe el Estagirita- es la virtud perfecta, mas no en general, sino en cuanto está referida a otro, por lo cual pasa por ser la más excelente de todas." "Cómo la virtud y esta justicia se distinguen a pesar de todo, (es decir, a pesar de que la justicia abarca a todas las virtudes), resulta claro por lo anterior. Ambas son lo mismo, pero su concepto no es el mismo, pues, en la medida en que se trata de una relación con otro, se habla de justicia, y en la medida en que se trata de un hábito que se manifiesta en actos justos, de la virtud a secas." 28

La forma de tratamiento en que la justicia consiste implica siempre cierta 'supraordinación', cierta 'relación de poder'. El que debe dar a otro un justo tratamiento hállase, eo ipso, supraordinado a él. "Veámos, a través de un ejempló, cómo se manifiesta dicha relación. La encargada del guardarropa tiene la posibilidad real de tratar en forma igual o desigual a los que asisten al teatro; el maestro está por encima de los alumnos; el crítico se halla en mejor posición que el ejecutante; el legislador detenta una parte del poder político, y ese poder le permite tratar a los ciudadanos igual o desigualmente. También en las representaciones del destino injusto y del Dios justiciero hay tal supraordinación: por una parte, el poder del destino; por otra, la omnipotencia de Dios." 29 Es la misma idea que Dante expresaba con las siguientes palabras: "En lo que al ejercicio de la justicia concierne. ésta encuentra asistencia en la fuerza, pues si es una virtud que ha de ser ejercitada frente a otro, ¿cómo podría alguien ser justo sin el poder de otorgar lo suyo a cada uno?". 30 Stahl, otro de los autores a quienes Nef cita al referirse a la norma de tratamiento, cscribe en forma todavía más clara: "Justicia, en el sentido originario y objetivo de la expresión, la atribuimos sólo al más alto, que establece la ley o la maneja, primeramente a Dios, luego

27 Nef, opus cit., pág. 75 .

28 Ética Nicomaquea, Libro V, I, $1129^{\mathrm{b}}$, cita de Nef en la pág. 76 de Gleichheit und Gerechtigkeit.

29 Nef, opus cit., pág. 77 .

30 Dante, De la monarquia, 39, cita de Nef en la pág. 77 de su ensayo. 
al príncipe o a cualquiera otra autoridad, al legislador, al juez, al padre, etcétera; pero no a los ciudadanos como tales, no a los iguales frente a los iguales". 31

\section{El elemento de la igualdad}

Ya el primer filósofo que habló sobre la justicia —dice Nef-- subrayó su conexión con la igualdad. "E gloria somma della filosofia italica o pitagorica l'avere, prima d'ogni altra, formulato un concetto della giustizia, che se non ne esprime intiera la verità, ne coglie senza dubbio ún aspetto fondamentale e specifico. La giustizia è, per cotesta scuola, innanzi tutto eguaglianza, vale a dire corrispondenza tra termini contraposti; e propriamente può assimilarsi al numero quadrato, ciò̀ all'uguale moltiplicato per l'uguale, perchè essa rende lo stesso per lo stesso." 32 Y Aristóteles, a quien nuestro autor llama "el verdadero maestro de la filosofía de la justicia", desprendió después de aquella idea todas las consecuencias que encierra. Lo que es injusto -dice el Maestro del Liceo_ vulnera la igualdad; lo justo es lo conforme a la ley y a la igualdad. ${ }^{33}$ Recordando una de sus doctrinas más famosas, Aristóteles añade: "Como todas las virtudes, la justicia es tambićn un medio. El término medio entre lo desigual, es decir, lo igual". ${ }^{34}$ El vínculo entre las dos nociones es después subrayado porr otros filósofos, especialmente por Cicerón y Santo Tomás.

Incluso en la definición de Ulpiano, que "no nació en el terreno de la filosofía, sino en el del derecho positivo", ${ }^{35}$ Nef encuentra una referencia a la igualdad. Cuando la justicia es definida como constans et perpetua volun: tas ius suum cuique tribuendi, la exigencia de que la voluntas sea constans y perpetua implica tal referencia. "Ocurre que los dos adjetivos se hallan" diferentemente matizados y sólo unidos cubren totalmente el concepto de igualdad, a que ambos apuntan. Perpetua indica que la voluntas ius suum cuique tribuendi debe existir en todo tiempo, que ha de perdurar $y$, en este sentido, ser igual... Constans alude más bien al contenido de la igualdad. La. voluntad ha de ser siempre igualmente firme, permanecer fiel a su contenido." 36 Aun cuando la definición romana tiéne el defecto de hallarse limitada al derecho positivo, cuya validez formal presupone sin plantear el problema ulterior de su justicia o injusticia intrinsecas, no puede negársele

31 Stahl, Philosophie des Rechts, II, 17, parte, 163, citado por Nef en la pág, $7^{8}$ de Gleichheit und Gerechtigheit.

32 Del Vecchio, La Giustizia, $229 \mathrm{f}$.

33 Ética Nicomaquea, Libro V, 3, 1131a, 10, cita en la pág. 80 de Gleichheit und Gerechtigheit.

34 Ética Nicomaquea, Libro V, 3, 1131a, 10, cita en la pág. 80 de Gleichheit und Gerechtigkeit.

35 Nef, opus cit., pảg. 81 .

36. Nef, opus cit., pág. 81. 
el mérito de haber subrayado, con aquellos adjetivos, "què también en esta forma de lo justo, en que lo que está en juego es sólo la aplicación del derecho vigente, la igualdad es esencial, en cuanto dicha aplicación debe ser duradera, perpetua y firme". ${ }^{37}$

\section{Especies de justicia}

Los ejemplos examinados deján ya entrever que la expresión 'igualdad de tratamiento' tiéne dos sentidos. En el primero alude a un tratamiento 'absolutamente' igual, que olvida o desdeña las diferencias de las personas. Asi, en el ejemplo del guardarropa, la encargada de repartir las prendas debe, para ser justa, ignorar aquellas diferencias y tratar a todos igualmente, a fin de que el tiempo de la espera sea el mismo para todos. En el caso del crítico, en cambio, el 'tratamiento igual' no significa 'juicio igual' en todos los casos, sino debido 'reconocimiento' de las 'diferencias' en el orden del mérito. En cuanto al maestro, debe proceder en forma 'estrictamente' igual cuando se trata de facilidades a que tienen derecho todos los alumnos; pero, al calificar. sus trabajos, no ha de conceder la misma nota a todos, sino calificar a cada uno según su rendimiento, de acuerdo con el mismo patrón de medida.

No sólo en los casos de 'justicia extrajurídica', sino en los de 'justicia jurídica', la igualdad consiste unas veces en que todos reciban lo mismo; otras, en que reciban cosas diferentes, en función del mérito o la culpa. "Pero si hay dos diferentes formas de igualdad de tratamiento, entonces tiene que haber, si la igualdad es la nota característica de lo justo, dos especies de justicia..." 38 "Aludimos — prosigue Nef- a la célebre distinción entre justicia conmutativa y distributiva. Conmutativa es aquella en que la igualdad de tratamiento encierra el sentido de que todos reciban o a todos se dé lo mismo: distributiva, aquella en que la igualdad consiste en la distribución de cosas desiguales, proporcionalmente a la desigualdad de los sujetos." 39

La cuestión medular es, pues, la siguiente: "¿existe un principio superior, de validez general, que permita establecer, en cada caso, qué especie de justicia hay que elegir?" 40 ¿O no existe tal criterio, y la elección tendrá que ser arbitraria?

Dos son las formas en 'que se ha tratado de resolver este problema. Algunos autores, siguiendo a Aristóteles, piensan que hay ciertos hechos o clases de hechos a los que, de acuerdo con su naturaleza, debe aplicarse la fórmula de la justicia igualadora, y otros hechos o clases de hechos a los que, también de acuerdo con șu naturaleza, debe aplicarse la fórmula de la justicia distributiva. Un segundo ensayo de solución consiste en buscar una sintesis

37 Nef, opus cit, pág. 83 .

38 Nef, opus cit., pág. 88 .

39 Nef, opus cit., pág. 89 .

40 Nef, opus cit., pág. 92. 
de las dos especies de lo justo, que vendría a ser, como escribe Nef, "la justicia más alta".

"De la justicia particular y el derecho que le corresponde -dice Aristóteles_ una de las especies. se refiere a la distribución de honores, dinero y otros bienes entre los ciudadanos, pues uno puede recibir más que otro o tanto como él; la otra es la que regula el comercio recíproco de aquéllos. La última tiene dos partes. Pues hay un comercio libre y otro no libre. Al libre corresponden, por ejemplo, la compra, la venta, el préstamo, la prenda, el usufructo, el arrendamiento. Aquí se habla de comercio libre porque el principio de tales contratos es el libre albedrio. Al comercio no libre pertenecen acciones en parte secretas, como el robo, el adulterio, el envenenamiento, la alcahuetería, la corrupción de esclavos, el asesinato a traición, el falso testimonio $y$, en parte, actos de violencia, como malos tratamientos, privación de la libertad, muerte, rapto, mutilación, difamación, envilecimiento." 41

La justicia distributiva debe normar la atribución, por el Estado, de recompensas o bienes; la conmutativa se aplica a las relaciones, contractuales o ilicitas, entre particulares. "Esta limitación de sectores cambia después, amplificándose en el aserto de que la justicia distributiva es propia del derecho público y la conmutativa del privado. Así, por ejemplo, Vico escribe: 'Justitia rectrix in publicis, aequatrix in privatis rebus obtinet'." Trendelenburg defiende la misma tesis. ${ }^{43}$

Nef considera que la solución aristotélica no es satisfactoria, porque el análisis del derecho positivo demuestra que los principios de justicia a que se alude en la Etica Nicomaquea no son exclusivamente aplicados a diferentes clases de normas, de acuerdo con su naturaleza. El ejemplo de los derechos de elección y de voto demuestra cómo la fórmula de la justicia conmutativa también se aplica intramuros del derecho público. Igualmente hay casos en que las dos fórmulas entran en juego. "Esto lo vemos en el derecho fiscal, que en determinados sectores jurídicos aplica ya el uno, ya el otro de los dos principios. El llamado impuesto personal es una emanación de la justicia conmutativa: a cada uno la misma carga, independientemente de su capacidad de rendimiento económico. Én cambio, los impuestos sobre la renta o, sobre capitales, en que las contribuciones están en relación con los ingresos o con el patrimonio, aplican la regla de la justicia distributiva."

“A la inversa: en el derecho privado de ningún modo es la justicia con-

41 Aristóteles, Ética Nicomaquea, Libro V, 2, $1130^{\mathrm{b}}, 30$, citado por Nef en la pág. 94 de su libro.

$42 \mathrm{~J}$. B. Vico, De uno universi iuris principio et fine, uno, 260, citado por Nef en la pág. 94 de Gleichheit und Gerechtigkeit.

43 Trendelenburg, Naturrecht auf dem Grunde der Ethik, citado por Nef en la pág. 95 de su obra. 
mutativa la única determinante. Siempre hay en ese ámbito diferenciaciones que se ajustan al otro principio. La capacidad jurídica general se basa en la justicia igualadora. Pero también hubo épocas en que no se aplicaba en forma tan amplia, y más bien dependía de ciertas diferencias entre los hombres. La situación de los cónyuges en el matrimonio es en muchos respectos completamente igual, pero en otros distinta, de acuerdó con las diferencias entre hombre y mujer. La exigencia de igualdad en la situación de los hijos legitimos y naturales se formula en nombre de la justicia conmutativa; las desigualdades obedecen al otro criterio." 44

Nef tampoco cree correcta la posición de quienes piensan, como Bodino, que lo más deseable es una síntesis de las dos justicias, que conduciría a una forma más alta, que el autor francés llama justitia harmonica. ${ }^{45}$ Pero, más que de una nueva especie, para Bodino se trata de un principio superior, que busca lo verdaderamente justo en una combinación de los otros criterios. La experiencia demuestra, en opinión de Nef, que los principios distinguidos por Aristóteles no permiten tal combinación, y "sólo pueden realizarse aisladamente, uno al lado de otro, pero no al mismo tiempo. La imposibilidad de la síntesis se advierte, por ejemplo, cuando en materia fiscal se quiere combinar el impuesto personal con el de la renta o capitales, lo que a la postre conduce a la imposición de contribuciones separadas, y no a la de una sola carga", ${ }^{46}$ Sỏlo en ciertas circunstancias - Nef las llama constelacioncs felices - pueden ambos principios ser realizados paralelamente. "Si tengo que repartir seis manzanas entre tres niños, la justicia conmutativa me indica que debo dar dos a cada uno, y la distributiva; por ejemplo, que he de dar tres al más aplicado, dos al siguiente en aplicación y una al menos diligente. Pero sólo puedo valerme de uno de los dos principios. Si quisiera realizar la justicia conmutativa, y luego la otra, tendría primeramente que dar una manzana a cada uno. Pero después ya no me sería posible proceder con las tres restantes de acuerdo con la justicia distributiva. Sólo lo podría hacer, si tuviera, verbigracia; nueve manzanas." 47

\section{Relatividad de la justicia}

El problema central de la doctrina de lo justo consiste, para Nef, en saber cuándo debe aplicarse el principio de la justicia conmutativa y cuándo el otro principio.

El que da lo mismo a todos lo hace basándose en una igualdad real $\mathrm{o}$, al menos, supuesta. Quien atribuye cosas desiguales, en cambio, atiende a

44 Nef, oprus cit., pág. 96.'

45 Bodino, Les six Livres de la République, jo6 ff., citado por Nef en la pág. 97 de Gleichheit und Gerechtigkeit.

46 Nef, opus cit., pág. 98.

47 Nef, opus cit., pág. 99. 
una desigualdad supuesta o de hecho. El maestro, al calificar las tareas de sus alumnos, se encuentra ante rendimientos diferentes, y debe calificar de acuerdo con el mérito de cada trabajo; el crítico musical, por su parte, debe aplicar también el principio distributivo, y medir "con la misma vara" a todos los ejecutantes. El legislador que concede iguales derechos de elección y de voto, juzga, en cambio, que todos los ciudadanos tienen la misma capacidad política, en tanto que el que limita esos derechòs está convencido de que tal capacidad no es igual en todo caso. Estos ejemplos revelan que el fundamento de cada especie de justicia se hace indefectiblemente residir ya en la igualdad, ya en la desigualdad de las personas o circunstancias a que se aplica. ¿Bastará entonces con sostener que si hay igualdad real debe aplicarse la justicia conmutativa, y si hay desigualdad real la justicia distributiva?... Pero ¿cuándo son los casos de aplicación realmente iguales o desiguales?

Si recordamos lo expuesto en un principio, y lo referimos a nuestro problema, tendremos que reconocer que "todo lo que es igual tiene, al menos en un respecto, que ser llamado desigual, amén de que, en la mayoría de los casos, los objetos que en una o varias relaciones son iguales, en otra u otras difieren. La igualdad y la diferencia se dan de modo concomitante, y las cosas son siempre iguales o desiguales en cierto respecto". ${ }^{48}$

¿Qué consecuencias encierra lo anterior para la doctrina de la justicia?

Si las cosas - responde Nef- son iguales y desiguales a un tiempo, entonces habrá que partir de ambos aspectos, el de la igualdad y el de la diferencia. Esto indica que deben ser tratadas igualmente desde el punto de vista de la igualdad y desigualmente desde el otro punto de vista. "Las dos formas de tratamiento tendrán entonces fundamento, serán objetivas, desde el ángulo visual de las cosas. Si las trato igualmente, invocaré su real igualdad para decir: 'igual a lo igual'. Si las trato desigualmente, invocaré su real desigualdad para decir: 'trato desigual a lo desigual'. Luego con estas fórmulas nada se adelanta. Parecen obvias, pero pierden valor práctico cuando queda en claro que todo lo comparable es, de modo simultáneo, igual y diferente, de manera que en los casos concretos ya no se sabe si lo que hay. que atribuir es lo igual o lo desigual." 49

Como todas las cosas - al menos en el orden del'ser real- son, a la vez, iguales y desiguales, siempre será posible encontrar un fundamento, sea para tratarlas igualmente, sea para tratarlas en forma distinta. La aplicación de una $u$ otra de las dos especies de justicia no está, pues, condicionada por las cosas mismas (que pueden justificar una o la otra), sino por el punto de vista que el sujeto adopta al juzgarlas.

"Si lo que me interesa es el ángulo desde el cual me parecen iguales, op- 
taré por la justicia conmutativa; si lo importante para mí es en cambio el mirador desde el cual parecen desiguales, me atendré a la justicia distributiva. Pero las cosas no me dicen qué punto de vista es el que debo adoptar. Por tanto, tampoco me indican por cuál de las dos justiciàs he de decidirme. $\mathrm{Y}$ así como no me enseñan qué posición he de asumir al juzgar de lo igual y lo desigual, tampoco me revelan si he de tratarlas como iguales o como diversas $o$, en otras palabras, si he de proceder de acuerdo con la justicia conmutativa o de acuerdo con la otra fórmula. Tal tarea me la dejan a mí; desde el punto de vista de las cosas tengo que proceder a mi arbitrio." 50

Y como la elección del 'punto de vista' está condicionada por la actitud del sujeto, el resultado de aquélla sólo puede ser relativamente correcto. Lo único que en forma universalmente válida cabe afirmar es que la justicia exige igualdad de tratamiento, y que tal igualdad ha de establecerse de acuerdo con uno de los dos mencionados principios. "Pero la elección no está regida por criterios universalmente válidos... Se da así, en el problema de la justicia, un peculiar enlace de lo universalmente válido y lo simplemente relativo, una dialéctica sui generis, que explica las interminables discusiones entre los autores." 51

Frente al problema del voto femenino, verbigracia, lo mismo puede fundarse una postura de defensa que la actitud contraria, ya que hombre y mujer son, a un tiempo, iguales y desiguales: iguales en su humanidad; diferentes en cuanto a su sexo. "Los defensores del voto de la mujer invocan la igualdad. En el caso no importa la desigualdad, sino la humanidad, por lo que deben otorgárseles los mismos derechos que a los hombres. Los enemigos del voto femenino, por el contrario, subrayan la desigualdad, sea la real, sea la legal correspondiente. La mujer, por su sexo, no estaría capacitada para participar en la formación de la voluntad estatal; no presta, como el hombre, servicio militar y, por tanto, también a consecuencia de ello parece justo negarle el derecho de voto. Tanto la afirmación de que el hombre y la mujer son iguales, como la contraria, resultan verdaderas. Si ha de tomarse en cuenta la igualdad o la desigualdad, no lo dice la teoría de la justicia. Ya no se trata, pues, de lo correcto o lo incorrecto, si bien los dos puntos de vista parten de algo que sí es objetivamente correcto." 62

Cosa análoga puede sostenerse, según Nef, en lo que atañe al problema racial: Para quienes establecen discriminaciones, la desigualdad de las razas es esencial y, por ende, hay que atribuirle consecuencias jurídicas; los que se oponen al trato discriminatorio declaran, en cambio, que las diferencias son inesenciales, y que "todo el que tiene rostro humano puede pretender que se le trate del mismo modo". "Otra vez dos posiciones que parten de algo

50 Nef, opus cit., pág. 106.

51 Nef, opus cit., pág. 108.

62 Nef, opus cit., pág. 109 . 
correcto. Pues también los hombres de razas distintas son, a un tiempo, iguales y desiguales entre sí. Por eso cabe decir que hay que darles lo mismo o, a la inversa, que debemos atribuirles cosas desiguales. En ambos casos se aplica una especie de justicia. Cuál de ellas sea la adoptada por mí, dependerá de la posición que asuma frente al problema de si debo considerar esencial la igualdad o la diferencia. Pero al escoger esa posición, el principio de justicia, que sólo exige igualdad de trato, no me sirve. Tendré, pues, que elegir de acuerdo con otros puntos de vista." 53.

Consideremos ahora el tratamiento que, en el ámbito del derecho penal, suele darse al delito consumado y a la tentativa. Actualmente empieza a generalizarse la opinión de que deben ser castigados en la misma forma; antes se consideraba justo sancionar la tentativa de modo más benigno, o no sancionarla en absoluto. Los hechos constitutivos de ambas figuras son, a un tiempo, iguales y desiguales entre sí: iguales en lo que respecta a la culpabilidad; diferentes en lo que concierne al resultado. Quienes atienden al primer aspecto, descuidando el segundo, opinan que las sanciones deben ser igualmente rigurosas; quienes, por el contrario, piensan que lo determinante es el resultado, proponen un tratamiento distinto para cada delito. "Nuevamente dos concepciones completamente diversas de la justicia, derivadas de que las mismas cosas aparecen una vez como iguales y otra como distintas. Pero, en realidad, son iguales y desiguales a un tiempo. Sólo que primeramente se las juzga en un respecto y luego en otro diverso." 54

En el derecho de los Estados federales encontramos otro ejemplo interesante. ¿Por qué se considera justa en dichos Estados - pregunta Nef- la organización de la Cámara de Senadores, a la que cada miembro de la Federación manda un número igual de representantes? Porque -responde el jurista suizo- Ios Estados federados son, a un tiempo, iguales y diferentes. Como entidades relativamente soberanas resultan iguales. Por ello merecen que su representación se organice de acuerdo con el principio conmutativo. Por su tamaño son distintos, y ello justifica la desigualdad de representación en la otra Cámara. "Una vez más - concluye Nef- nos hallamos ante consideraciones, condicionadas por distintos puntos de vista, de cosas que son, a un tiempo, iguales y desiguales entre sí." 55

Pero si la teoria de la justicia no puede ofrecernos, en los casos concretos, soluciones universalmente válidas, con ello no queda dicho que sea imposible decidir qué forma de lo justo debe aplicarse y resulta, cada vez, objetivamente correcta. La posibilidad de establecer la corrección objetiva de una solución es independiente - para Nef- de la relatividad del criterio de justicia, ya que, aunque éste resulte insuficiente, existen pautas de acuerdo

53 Nef, opus cit., pág. 110.

54 Nef, opus cit., pág. 111.

55 Nef, opus cit., pág. 112. 
con las cuales la elección de una u otra de las dos especies de lo justo puede ser justificada.

"Tratemos nuevamente de mostrarlo con ayuda de nuestros ejemplos.

"La justicia no nos dice si hay que conceder a todos los ciudadanos el mismo derecho de elección y de voto, 'o si conviene establecer gradaciones de acuerdo con las capacidades atribuidas en materia política a cada uno. En otras palabras: no nos indica si hay que aplicar el principio conmutativo o el distributivo. Ambas cosas son justas. Pero ello no impide que en un Estado determinado y en cierta época pueda muy bien decirse qué es lo objetivamente correcto. Habrá que preguntar de qué manera queda mejor garantizada la solución de los asuntos públicos. Se investigará qué es más útil, políticamente hablando, y qué puede realizarse con mayor facilidad en la práctica. Habrá que esclarecer qué corresponde mejor al desarrollo histórico y a la șituación del Estado, así como a la condición intelectual de los ciudadanos. Todos éstos son puntos de vista a cuya luz se juzgará lo absolutamente correcto, pero puntos de vista que ya no tienen que ver con la justicia.

"Si el derecho de voto de la mujer debe ser introducido es algo que desde el ángulo visual de la justicia no cabe afirmar ni negar de modo universalmente válido. Pero la decisión correcta puede ser hallada recurriendo a otros principios. Tendremos que examinar, por ejemplo, si la mayoría de las mujeres quiere tener ese derecho, si se interesa suficientemente en los asuntos públicos y si con ello no sufrirán otros aspectos de la actividad femenina.

"En resumen: que en los casos especiales no pueda decirse con validez universal, desde el punto de vista de la justicia, qué especie de lo justo hay que elegir, en modo alguno excluye que, por aplicación de otros criterios, pueda llegarse a la solución objetivamente correcta." 56

\section{La justicia en el derecho}

La anterior conclusión conduce a Nef a otro punto. Si efectivamente existen criterios, fuera de la doctrina de lo justo, a cuya luz sea posible escoger en cada caso la fórmula aplicable (adecuación a un fin, necesidades vi- . tales, responsabilidad, etc.), entonces resulta que el derecho, en su aspecto material, no es determinado sólo por la justicia, sino por principios de otra clase.

Por ejemplo: todo legislador se enfrenta siempre al problema de si debe o no organizar una fuerza militar. La pregunta suele ser afirmativamente respondida, no por razones de justicia, sino porque el Estado necesita, para conservarse, que tal fuerza exista. "Si es justo o injusto tener un ejército es

56 Nef, opus cit., pág. 116. 
cuestión que no se plantea. Nadie hablará en el caso de justicia o injusticia. Respondida la pregunta en sentido afirmativo, surge, de modo necesario, el ulterior problema de la organización de la milicia. ¿Habrá que crear un ejército popular o profesional, milicias armadas o tropas permanentes? Al contestar estos interrogantes tampoco se pensará en la justicia o en su contrario. Se obrará de acuerdo con reglas de oportunidad o de adecuación a los fines perseguidos. ¿QQué es mejor, más adecuado, más eficaz? Esto es lo que se pondrá en cuestión, no ¿qué es más justo?" $n$

Pongamos otro ejemplo. Numerosos códigos dè procedimiento civil establecen que, antes del litigio propiamente dicho, debe existir un procedimiento conciliatorio. Con ello se quiere crear una oportunidad para que, de ser posible, las partes lleguen a un acuerdo, no sólo en su propio interés, sino en beneficio del poder judicial, cuyo trabajo no debe ser recargado en forma innecesaria. La institución a que aludimos no ha sido creada por razones de justicia, sino por consideraciones de utilidad práctica y economía de esfuerzo. "Nadie encontrará justo o injusto, sino adecuado o inadecuado a ciertos fines que el procedimiento conciliatorio exista. Lo revela también el hecho de que en casos particulares en que se prevé un procedimiento especial, no tiene lugar el de conciliación. En tales casos no parece más justo que no haya antes un procedimiento de esa especie, sino más conveniente o idóneo." ธ8

Ejemplifiquemos, por último, con las finalidades atribuidas al castigo, en materia penal. Por importante que sea el papel de la llamada retribución, como exigencia de la justicia, no hay duda de que el ejercicio del derecho de castigar es también considerado como medio de realización de fines muy distintos del puramente retributivo. El que castiga al delincuente con la mira de hacerlo otra vez capaz de vivir en la comunidad, no basa el sistema penal sólo en la idea de lo justo. Lo decisivo para él no es imponer un sufrimiento al delincuente, sino lograr su regeneración. "Quien parte de la idea de la prevención tendrá, a su vez, que llegar a otros resultados. Las diferentes posturas aparecen con gran nitidez cuando se discute la pena de muerte. Ésta puede ser justificada bien desde el punto de vista de la justicia retributiva, bien por la necesidad de suprimir al autor de delitos graves, bien, por último, en ciertas circunstancias, de acuerdo con un propósito de intimidación y prevención." 59

Estos ejemplos revelan que el contenido de las normas juridicas no está exclusivamente determinado por principios de justicia. El 'derecho justo' no coincide siempre con el 'correcto' (richtiges Recht). La corrección (o validez intrinseca) de aquellas normas se establece de acuerdo con criterios que nada

67 Nef, opus cit., pág. 119. 58 Nef, opus cit., pág. 121.

50 Nef, opus cit., pág. 123. 
tienen que ver con el de lo justo. Ponderar la relativa importancia de todos ellos y, por ende, la jerarquía de los valores que el orden jurídico debe realizar, es problema que, en opinión de Nef, rebasa el marco de la teoría de la justicia.

\section{Discusión de algunos aspectos de la tesis de Nef}

El mayor mérito de la doctrina expuesta reside para nosotros en el análisis del concepto de igualdad. Quien desee esclarecer las relaciones entre éste y el de justicia deberá, ante todo, profundizar la primera de las dos nociones, cosa que Nef ha hecho de modo admirable.

Los reparos que deseamos exponer aquí, más que al desarrollo de la tesis, refiérense a su conclusión última, es decir, a lo que podríamos llamar el relativismo de nuestro autor.

Este aspecto descansa, para Nef, en un principio al que concede validez absoluta: la justicia consiste en tratar igualmente lo igual y desigualmente lo desigual, en proparción a su desigualdad.

Pero como las cosas son, al propio tiempo, iguales y desiguales, vale decir, iguales en ciertos respectos y diferentes en otros, resulta obvio - según el jurista suizo - que deben ser tratadas igualmente desde el punto de vista de la igualdad y desigualmente en lo que atañe a sus diferencias.

Tal convicción lo lleva al aserto de que las dos formas de tratamiento son igualmente correctas, desde el ángulo visual de las cosas. "Si las trato igualmente, puedo invocar su real igualdad y decir: 'igual a lo igual'. Si las trato desigualmente, invocaré su real desigualdad para decir: 'trato desigual a lo desigual',"

Pero si las cosas no me indican qué posición debo asumir al juzgarlas, tampoco me enseñan cuál de las dos formas de justicia es la que en cada caso deberé aplicarles. Si no me revelan qué es en ellas más importante, la igualdad o la desigualdad, tendré que atenerme, al juzgarlas, a lo que 'me parezca decisivo. Y esta elección estará, a su vez, en lo que concierne a la igualdad o desigualdad de los objetos, subjetivamente condicionada, en el sentido de que la solución nunca podrá derivar de las cosas mismas.

Recuérdese en qué forma, a la luz de diversos ejemplos, pretende Nef corroborar las anteriores consideraciones.

Esta faceta de su doctrina es la que parece más discutible. Por ello no estoy de acuerdo con la forma en que analiza sus ejemplos.

Volvamos, por lo pronto, a uno de ellos, el del problema racial.

Según Nef, tan objetiva es la posición de quienes establecen discriminaciones en el trato de acuerdo con diferencias de raza, como la postura de los que exigen un tratamiento igual, por considerar que 'en su humanidad y dignidad' todos los hombres son iguales. ¿Por qué piensa Nef que las dos 
especies de tratamiento son justas? Porque, en su concepto, una y otra poseen un fundamento objetivo. El de la primera residiría en la diferencia real de las razas (el blanco no es negro, el negro no es amarillo, etc.); el de la segunda, en la igualdad real de los hombres en cuanto tales. "Los de razas distintas — dice— son, a un tiempo, iguales y desiguales entre sí. Por eso puede sostenerse que hay que darles lo mismo o, a la inversa, que debemos atribuirles cosas desiguales." En ambos casos estaremos en presencia, según él, de una diferente especie de justicia. '

Lo que parece más dudoso es el aserto de que, 'desde el punto de vista de las cosas' - y obsérvese que en el caso no se trata de cosas, sino de personasresulta imposible establecer cuál de los dos tipos de tratamiento es correcto. Si a hombres de razas distintas hay que tratarlos de acuerdo con la justicia conmutativa o, por el contrario, según la distributiva, no es, para Nef, problema de justicia, sino cuestión que sólo cabe resolver a la luz de criterios que ya no puede brindarnos la doctrina de lo justo.

Pero vayamos por partes. ¿Es cierto, en primer término, que la discriminación racial sea, en el sentido que Nef expresa, tan justa como la igualdad de tratamiento?

Si lo fuera, podríamos considerar igualmente justa cualquier forma de trato basada en diferencias de orden físico o biológico distintas de las raciales. Habría entonces que decir, por ejemplo, que el tratamiento igual -en lo que a los hombres respecta- es tan justo, y tan objetivo, como cualquiera forma de discriminación impuesta por el legislador a los calvos o a los barrigudos. Pues también los barrigudos y los calvos - en cuanto talesson distintos de los no barrigudos y los no calvos, y ello en el mismo sentido en que un negro, por el color de su piel, difiere de un blanco o de un amarillo.

Sostener, como nuestro autor, que cualquier diferencia en los objetos -0 , lo que es más grave, en las personas- justifica la desigualdad de tratamiento, equivale a privar de sentido a la noción de justicia, sobre todo si se afirma que la selección y valoración de las notas comunes o diversas depende de apreciaciones subjetivas. Pues como el número de esas notas es infinito, siempre se podrá declarar que alguna -o algunas- de ellas fundamentan ya la igualdad, ya la desigualdad.

El verdadero problema no consiste en descubrir semejanzas o diferencias creyendo que con ello se justifica cualquiera especie de tratamiento, sino en determinar qué notas tienen y cuáles no tienen relevancia jurídica. Volviendo a los ejemplos diremos, pues, que las diferencias de color, o cualesquiera de orden físico o biológico, jamás podrán justificar ninguna regulación contraria a la dignidad humana, porque ésas diferencias carecen de valor e importancia frente a la igualdad fundamental de los hombres como tales. 
Insistiendo en el ejemplo, no podemos admitir, por ende, que la discriminación racial sea tan justa $u$ objetiva como la igualdad de tratamiento. ¿No es precisamente el trato discriminatorio que a veces se aplica a individuos de otras razas lo que más profundamente hiere nuestro sentimiento de justicia? ¿Y cómo podría herirlo si nada tuviera que ver con el problema de lo justo?

La teoría que discutimos no puede, pues, concluir en el punto que Nef señala, pues su problema básico consiste en determinar — de acuerdo con notas jurídicamente esenciales- cuándo debe aplicarse un trato igual y cuándo un trato diferente o, para expresarlo en otro giro, cuándo hay que recurrir a la fórmula de la justicia igualadora y cuándo a la de la justicia distributiva.

Con esto no queremos decir que la determinación de la validez intrínseca de las normas jurídicas dependa siempre de consideraciones de justicia. Pues, como Nef correctamente lo señala, aquel atributo deriva a veces de la realización -por tales normas- de valores distintos del de lo justo. No es, por tanto, este aspecto el que suscita nuestras objeciones, sino el relativismo de su doctrina.

La falla principal de ésta consiste, a nuestro entender, en la creencia de que las diversas formas de tratamiento jurídico encuentran su justificación inmediata en la igualdad o la diferencia de los objetos, personas o situaciones a que se aplican.

Obsérvese que dichas formas en todo caso se traducen en juicios normativos. Éstos consisten unas veces en la imposición de obligaciones; otras, en el otorgamiento de derechos. Su fundamento depende, según nuestro autor, de la igualdad o la desigualdad de los casos de aplicación de cada precepto. Los juicios que establecen la igualdad o la diferencia no son normativos, sino enunciativos. Ni imponen deberes ni conceden facultades; limítanse a comprobar igualdades o diferencias entre dos o más situaciones o personas. Pero si de la observación de los hechos no es correcto desprender -como decía Kant- conclusiones normativas, las normas del derecho no pueden encontrar su justificación en los juicios de igualdad o diferencia.

Como todo lo comparable es también, al propio tiempo, igual en ciertos respectos y desigual en otros, siempre será posible, de acuerdo con la doctrina que discutimos, fundar cualquier tipo de tratamiento, ya el que aplica la fórmula de la justicia conmutativa, ya el que da aplicación al otro criterio. Sostener que toda norma que se base en el reconocimiento de igualdades o diferencias entre los casos que regula queda, eo ipso, justificada, en el fondo equivale a decir que ninguna se justifica, puesto que lo que se afirma de la que establece un trato igual se asevera asimismo de las de carácter discriminatorio.

- Las normas no descansan de manera inmediata en juicios enunciativos 
sobre la igualdad o la diferencia de los casos que regulan. Entre aquéllas y éstos aparecen siempre ciertos juicios valoradores, ya de la igualdad, ya de la diferencia de las situaciones a que se aplican.

La norma jurídica deriva de modo directo del juicio de valor, y no del que comprueba igualdades o diferencias. La relación entre las tres especies de juicios puede ejemplificarse asi:

1) 'El sujeto $A$ es igual al sujeto $B$ en el respecto $C$ ' (juicio de igualdad).

2) 'La igualdad de $A$ y $B$ en el respecto $C$ es jurídicamente esencial' (juicio de válor).

3) 'El sujeto $A$ tiene derecho a ser tratado, en el respecto $C$, en forma igual que el sujeto $B^{\prime}$ ' (norma de tratamiento).

Cuando las diferencias entre las personas se consideran jurídicamente esenciales o, lo que es lo mismo, cuando se juzga que deben producir consecuencias de derecho, la relación se expresa de este modo:

1 a) 'El sujeto $A$ es diferente del sujeto $B$ en el respecto $C$ ' (juicio de diferencia).

2 a) 'La diferencia entre $A$ y $B$ en el respecto $C$ es jurídicamente esencial' (juicio de valor).

3 a) 'El sujeto $A$ y el sujeto $B$ deben ser desigualmente tratados en el respecto $C^{\prime}$ (norma de trato).

Declarar que determinadas diferencias entre dos o más sujetos son jurídicamente esenciales, en el fondo equivale a sostener que aquel a quien se atribuye mayor valor, en tal o cual respecto, debe, en ese respecto, tener mayores derechos.

La relación entre los tres juicios puede entonces ejemplificarse así:

a b) 'El sujeto $A$ y el sujeto $B$ son diferentes en el respecto $C$ ' (juicio de diferencia).

2 b) 'El sujeto $A$ vale más que el sujețo $B$ en el respecto $C$ ' (juicio de valor).

3 b) 'El sujeto $A$ debe tener, en el respecto $C$, mayores derechos que el sujeto $B^{\prime}$ (norma de tratamiento).

Cuando lo que se declara esencial es la igualdad de los hombrés entre sí, los juicios se formulan de esta guisa:

a c) 'Todos los hombres, en cuanto hombres, son iguales entre si' (juicio de igualdad). valor).

2 c) 'Todos los hombres, en cuanto tales, valen lo mismo' (juicio de

3 c) 'Todos los hombres, en cuanto tales, deben ser igualmente tratados' (norma de tratamiento).

Estos ejemplos revelan que ni la igualdad ni la diferencia justifican, por si mismas, la igualdad o la desigualdad en el trato. Lo decisivo, desde el punto de vista jurídico, no es la comprobación de que ciertos hechos, situa- 
ciones o personas difieren o, por el contrario, son iguales en tal o cual respecto; lo decisivo es el juicio de valor sobre las igualdades o diferencias a que los otros juicios dan expresión.

Así como las reglas 'técnicas descansan siempre en principios científicos cuya aplicación condiciona la eficacia de las mismas reglas, los preceptos del derecho $y$, en general, todas las normas, poseen también un fundamento, pero de otra especie. No consiste ya, como en el primer caso, en verdades cientificas, sino en proposiciones de índole axiológica. Esta relación entre juicios normativos y valoraciones ha sido esclarecida por Husserl en los "Prolegómenos" a sus justamente célebres Investigaciones Lógicas. ${ }^{60}$

El ilustre autor niega que el sentido primitivo del deber haya de referirse a un desear o querer, a una exigencia o un mandato como, por ejemplo, "tú debes obedecerme", " $X$ debe venir a mi casa". "Así como en un sentido amplio hablamos de una exigencia, incluso donde no hay nadie que exija, ni eventualmente nadie tampoco a quien exigir, así también hablamos con frecuencia de un deber, prescindiendo de todo desear o querer." ${ }^{1}$. Si declaramos: "un guerrero debe ser valiente", esto no significa que nosotros ni nädie deseemos o queramos, ordenemos o exijamos tal cosa. Mejor cabría sostener la opinión de que semejante caso y exigencia está justificado en general, esto es, con respecto a todo guerrero. Pero tampoco esto es completamente exacto; pues no es necesario que tenga lugar realmente semejante valoración de un deseo o una exigencia. ${ }^{62}$ Lo que aquel juicio propiamente dice es que sólo es un "buen" guerrero el valeroso, lo que al propio tiempo supone que el que no lo sea será un "mal" guerrero, puesto que los predicados bueno y malo agotan la extensión del concepto guerrero. Si inquirimos qué puede justificar la exigencia contenida en dicha proposición, habrá que responder que su fundamento está en el juicio de valor que afirma que "sólo es bueno el guerrero valiente". Como este juicio es válido, tiene razón todo aquel que exija de un guerrero la indicada virtud. "Por el mismo, motivo es deseable, loable, etc., que la tenga." Y lo propio en otros ejemplos. "El hombre debe amar al prójimo", es decir, quien no lo haga no es un hombre "bueno"; y es, eo ipso, un hombre "malo" (en este respecto). "Un drama no debe disolverse en episodios"; de lo contrario, no es un "buen" drama, una "verdadera" obra de arte. En todos estos casos hacemos depender nuestra valoración positiva, la concesión de un predicado de valor positivo, del cumplimiento de una condición, cuyo incumplimiento trae consigo el predicado negativo correspondiente. En general podemos considerar como iguales, $o$ al menos como equivalentes, estas fórmulas: "un $A$ que debe ser $B$ " y "un $A$ que no es $B$ es un mal $A$ " o "sólo un " $A$ que es $B$ es un buen $A$ ". ${ }^{83}$

60 Capítulo II, $\S 14$

61 HusserI, Investigáciones Lógicas, Vol. I, pág. 57 de la traducción de Morente y Gaos.

62 Husserl, Invéstigaciones Lógicas, Vol. I, pág. 57 de la traducción castellana.

63 Husserl, obra y traducción citadas, Vol. I, pág. $5^{8}$. 
La validez de las normas jurídicas depende, pues, de que sea posible fundarlas en el juicio de valor que atribuye un predicado axiológico positivo a la conducta cuya realización esas normas exigen, ya de un sujeto, ya de todos los de cierta clase.

El problema básico de la teoría de la justicia no consiste en determinar la igualdad o la diferencia de los casos de aplicación de los diversos preceptos, sino en establecer, relativamente a situaciones concretas de la experiencia juridica, qué consecuencias de derecho tales situaciones deben producir.

Los juicios sobre valores jurídicos tienen su origen, según Mircea Djuvara, en el examen y apreciación de casos singulares; por ello llevan, directamente, a normas especiales o individualizadas. ${ }^{64}$ Esto no excluye, como es obvio, a las de carácter general o abstracto. No sólo se puedé decir -de acuerdo con el jurista rumano- que en tales o cuales circunstancias determinado individuo debió abstenerse de robar tal o cual cosa a otra persona; también es posible establecer, generalizando, la regla de que la propiedad ajena debe ser respetada.

Cuando, frente a casos concretos de la vida jurídica, se valora una situación con el propósito de señalarle consecuencias de derecho (facultades o deberes), tanto el juicio de valor como la norma de que se parte tienen carácter singular; al precepto abstracto se llega después, gracias a un razonamiento de tipo inductivo.

"Toute réalité sociale se réduit; en effet, en fin de compte, à une série d'actions concrètes accomplies par des individus dans une société donnée. Nous reconnaissons ainsi à tel individu à propos de telle action déterminée qu'il a ou qu'il n'a pas le droit de la faire, qu'il est obligé ou qu'il n'est pas obligé de la faire.

"Il y a cependant aussi des normes générales que la raison semble poser. Nous disons par exemple, même en dehors de tout droit positif, non seulement que tel individu déterminé n'a pas eu le droit dans un cas particulier de voler un autre individu déterminé, mais aussi que personne n'a le droit de voler son semblable." 65

¿Por qué se formula la norma general que prohibe robar? ¿Cuál es la razón de su validez?

El procedimiento que según Djuvara se sigue para establecerla no difiere, lógicamente, del que conduce a las proposiciones generales sobre las propiedades del cloro, ya que tanto en un caso como en el otro se parte de juicios singulares, que luego son generalizados. "Si, en effet, on n'avait jamais eu l'occasion de constater ou d'imaginer un vol individuel, il est évident que l'on n'aurait jamais pu émettre l'énonciation générale que le vol est défendu.

64 Mircea Djuvara, "Droit rationnel et droit positif", en Recueil d'études sur les sources $d u$ droit, en l'honneur de François Gény, Vol. I, págs. 245-277.

65 Djuvara, obra y artículo citados, pág. 253. 
"Les normes individuelles, c'est-à-dire les jugements individuels de justice, émis à l'occasion d'actions humaines déterminées concrétement, sont ainsi à la base de toute généralisation juridique." 6

Hay que tener en cuenta, sin embargo, que si bien la norma abstracta se obtiene por generalización partiendo de la correspondiente individual, ésta se basa de modo inmediato en un juicio de valor.

Cuando la generalización se hace, el precepto abstracto no vale solamente para el caso concreto que se tuvo a la vista al formular el juicio dé valor y la norma individuales (o rectores del propio caso), sino para todos los hechos del mismo jaez. Los conceptos integrantes de las normas jurídicas de índole abstracta derivan del método generalizador de conceptuación empleado por el autor de la ley, ${ }^{67}$ y son, por ende, conceptos de clase. Por ello no están referidos a la iridividualidad de determinados hechos juridicos, sujetos, facultades o deberes, sino a hechos, personas, obligaciones o derechos dé cierto género. 68

La formación de clases o categorías de hechos, personas, derechos, etc., que resultan iguales en tal o cual respecto; no obedece empero al prurito de comprobar la igualdad de los que pertenecen a cada grupo, "sino al propósito de imponer la obligación de que se les trate del mismo modo. Pues, como escribe Ch. Perelman, "être juste c'est traiter de la même façon les êtres qui sont égaux à un certain point de vue, qui possédent une même caractéristique, la seule dont il faille tenir compte dans l'administration de la justice" ${ }^{69}$ La justicia 'formal' o 'abstracta' debe, pues, ser definida, en opinión del autor belga, como "un principe d'action selon lequel les êtres d'une mème catégorie essentielle doivent être traités de la même façon".70

La igualdad - relativamente a quien forma parte de una misma clase - 'categoría esencial' - es, como el propio Perelman lo subraya, "una consecuencia de la regularidad",71 puesto que la "justicia formal' se reduce "a la aplicación correcta de una regla".

Pero entonces resulta que lo esencial, desde el punto de vista de la justicia, no es la igualdad o la diférencia de las situaciones que son objeto de regulación juridica, sino la determinación de las consecuencias de derecho que, de acuerdo con la naturaleza de tales situaciones, deben éstas producir. Que las que se atribuyen a un caso concreto sean despuéś imputadas, por generalización de la norma individual, a todos los-de la misma especie, no es algo que derive de la comprobación de su igualdad, sino de la operación

60 Djuvara, obra y artículo citados, pág. 254.

67 Cf. E. Garcia Máynez, Lógica del Concepto Jurídico, Cap. I, 11, Publicaciones de Diánoia, Fondo de Cultura Económica, ${ }^{-M e ́ x i c o, ~} 1959$.

68 E. Garcia Máynez, Lógicá del Concepto Jurídico, I, 11, pág. 47.

69 Ch. Perelman, De la-justice, Office de Publicité, Bruxelles, 1945, pág. 27.

70 Perelman, opus cit., pág. 27.

71 Perelman, opus cit., pág. $5^{6}$. 
generalizadora. En otras palabras: si todos esos casos son regulados del mismo modo, no es porque sean como otros, sino porque son como son. Lo que en cada caso importa no es que sean como los demás de la clase, sino que tengan las características que justifican que el autor de la ley les atribuya tales o cuales consecuencias normativas. La igualdad de tratamiento no es, pues, fundamento, sino consecuencia del carácter general de la regla que los convierte en 'casos' de su propia aplicación. ${ }^{72}$ Por eso hemos sostenido, contrariamente a la opinión de Nef, que a la formulación de normas justas no puede llegarse cuando se han descubierto determinados nexos de igualdad o diferencia entre las situaciones que son objeto de regulación, pero no se han valorado esas igualdades o diferencias, ni se ha determinado qué consecuencias de derecho han de atribuirse a cada caso.

\section{Eduardo García Máynez}

\footnotetext{
72 Después de poner diversos ejemplos, con la mira de demostrar cómo normas diferentes pueden crear equivalencias o relaciones de igualdad entre personas que pertenecen a distintas categorias, Enrico di Robilant escribe: "Appare chiaro che le norme esaminate, pur stabilendo dele equivalenze, dei rapporti di uguaglianza fra consociati appartenenti a categorie diverse, non possono dirsi ispirate al criterio dell'uguaglianza, poiché non traggono la loro giustificazionc dal principio secondo cui giustizia è dare a tutti nella medesima misura, ossia trattare tutti i consociati nello stesso modo. Esse, infatti, non stabiliscono un trattamento uguale per tutti $i$ consociati, anzi, istituendo equivalenze fra singole categorie di essi, implicano una disuguaglianza di trattamento rispetto ad altre categorie. Le equivalenze institui, perciò, sono la conseguenza dell'aplicazioné di un determinato trattamento a una categoria di consociati composta dai membri di due o più altre categorie, distinte, naturalmente, in base a un diverso elemento specifico, ossia, secondo la terminologia del Perelman, in base a una diversa caratteristica essenziale. Il legislatore ritiene, in altri termini, che consociati $\mathrm{i}$ quali, per certi aspetti, appartengono a categorie diverse, per un altro aspetto appartengono invece a una medesima categoria, e perció applica loro un medesimo trattamento. Il contenuto di quest'ultimo, tuttavia, ripete la sua giustificazione da criteri diversi dall'uguaglianza. Il fatto, cioè, chè coloro i quali, a determinati effetti, vengono considerati appartenenti ad una medesima categoria, ricevano un trattamento piuttosto che un altro, trova la sua giustificazione in un criterio diverso $d a$ quello dell'uguaglianza." Sui Principi di Giustizia, Milano, Dott. A. Giuffrè, Editore, 196r, pág. 85 .
} 